\title{
State-Dependent Alterations in Hippocampal Oscillations in Serotonin 1A Receptor-Deficient Mice
}

\author{
Joshua A. Gordon, ${ }^{1,2,4}$ Clay 0. Lacefield, ${ }^{1}$ Clifford G. Kentros, ${ }^{5}$ and Rene Hen ${ }^{1,2,3,4}$ \\ ${ }^{1}$ Center for Neurobiology and Behavior, Departments of ${ }^{2}$ Psychiatry and ${ }^{3}$ Pharmacology, Columbia University, New York, New York 10032, ${ }^{4}$ New York State \\ Psychiatric Institute, New York, New York 10032, and Institute of Neuroscience, Department of Psychology, University of Oregon, Eugene, Oregon 97403
}

\begin{abstract}
Mice lacking the serotonin $1 \mathrm{~A}$ receptor $\left(5-\mathrm{HT}_{1 \mathrm{~A}} \mathrm{R}\right)$ show increased levels of anxiety-related behavior across multiple tests and background strains. Tissue-specific rescue experiments, lesion studies, and neurophysiological findings all point toward the hippocampus as a potential mediator of the phenotype. Serotonin, acting through $5-\mathrm{HT}_{1 \mathrm{~A}} \mathrm{Rs}$, can suppress hippocampal theta-frequency oscillations, suggesting that theta oscillations might be increased in the knock-outs. To test this hypothesis, local field potential recordings were obtained from the hippocampus of awake, behaving knock-outs and wild-type littermates. The magnitude of theta oscillations was increased in the knock-outs, specifically in the anxiety-provoking elevated plus maze and not in a familiar environment or during rapid eye movement sleep. Theta power correlated with the fraction of time spent in the open arms, an anxiety-related behavioral variable. These results suggest a possible role for the hippocampus, and theta oscillations in particular, in the expression of anxiety in 5- $\mathrm{HT}_{1 \mathrm{~A}} \mathrm{R}-$ deficient mice.
\end{abstract}

Key words: anxiety; theta rhythm; knock-out; 5- $\mathrm{HT}_{1 \mathrm{~A}}$ receptor; ripple oscillations; awake behaving recording

\section{Introduction}

Anxiety and its disorders are sensitive to serotonergic agents, including serotonin reuptake inhibitors and agonists of the serotonin $1 \mathrm{~A}$ receptor $\left(5-\mathrm{HT}_{1 \mathrm{~A}} \mathrm{R}\right)$ (Den Boer et al., 2000; Gordon and Hen, 2004). It is not surprising, therefore, that mice with a targeted deletion of the $5-\mathrm{HT}_{1 \mathrm{~A}} \mathrm{R}$ show increased levels of anxietyrelated behaviors on several different tasks (Heisler et al., 1998; Parks et al., 1998; Ramboz et al., 1998). The recent finding of decreased 5- $\mathrm{HT}_{1 \mathrm{~A}} \mathrm{R}$ binding in a positron emission tomography imaging study of panic disorder patients underscores the value of studying these mice as a model of human anxiety disorders (Neumeister et al., 2004). Understanding the precise mechanisms by which genetic deletion of the $5-\mathrm{HT}_{1 \mathrm{~A}} \mathrm{R}$ leads to increased anxiety-like behavior promises to shed light on the neurobiology of anxiety.

Using a tissue-specific, inducible rescue approach, Gross et al. (2002) showed that postsynaptic $5-\mathrm{HT}_{1 \mathrm{~A}} \mathrm{Rs}$ are required during development for normal anxiety-like behavior in adulthood, suggesting that receptor deletion affects the formation of neural cir-

\footnotetext{
Received March 29, 2005; revised May 26, 2005; accepted May 31, 2005.

This work was supported by National Institutes of Health Grants P01 MH48125 (R.H.) and K08 MH069823 (J.A.G.). R.H. is a National Alliance for Research on Schizophrenia and Depression (NARSAD) Distinguished Investigator. J.A.G. is a NARSAD-Bowman Family Foundation Young Investigator and was supported by a Pfizer Biological Psychiatry Postdoctoral Fellowship and a Sackler Foundation Fellowship in Developmental Psychobiology. We thankE. Kandel, N. Agnihotri, G. Buzsaki, D. Buhl, and K. Harris, as well as other members of the Buzsaki laboratory, for providing advice, assistance, and software routines for performing the experiments and analyses described here. J. Mor assisted with the ripple analysis. We also thank D. Leonardo, A. Dranovsky, G. Buzsaki, and C. D. Salzman for helpful comments on this manuscript.

Correspondence should be addressed to Joshua A. Gordon, Center for Neurobiology and Behavior, Department of Psychiatry, Columbia University/New York State Psychiatric Institute, 1051 Riverside Drive, Unit 87, New York, NY 10032.E-mail:jg343@columbia.edu.

DOI:10.1523/JNEUROSCI.1211-05.2005

Copyright $\odot 2005$ Society for Neuroscience $\quad$ 0270-6474/05/256509-11\$15.00/0
}

cuits that regulate anxiety. However, precisely which circuits are disrupted in the absence of the $5-\mathrm{HT}_{1 \mathrm{~A}} \mathrm{R}$, and what specific functional properties are altered? Several lines of evidence suggest the hippocampus as a likely candidate region. Although the rescue directed expression of the $5-\mathrm{HT}_{1 \mathrm{~A}} \mathrm{R}$ to numerous areas, including the amygdala, the hippocampus and neocortex are the principle regions of overlap between wild-type and rescue expression patterns (Gross et al., 2002). The receptor is normally expressed most highly in the CA1 region of the hippocampus (Chalmers and Watson, 1991; Gross et al., 2002). Defects in hippocampal function have been documented in $5-\mathrm{HT}_{1 \mathrm{~A}} \mathrm{R}$ knock-outs, including impaired paired-pulse facilitation and inhibition (Sarnyai et al., 2000; Sibille et al., 2000). 5- $\mathrm{HT}_{1 \mathrm{~A}}$ receptor agonists injected directly into the hippocampus alter anxiety-related behaviors in the same tasks in which the knock-outs behave abnormally (Kostowski et al., 1989; Stefanski et al., 1993; File and Gonzalez, 1996; File et al., 1996). Finally, there are profound effects of direct $5-\mathrm{HT}_{1 \mathrm{~A}} \mathrm{R}$ activation on hippocampal physiology, including hyperpolarization of pyramidal neurons, as well as decreased magnitude of theta-frequency oscillations (Andrade and Nicoll, 1987; Hirose et al., 1990; Tada et al., 1999). Theta oscillations are 4-12 $\mathrm{Hz}$ waves present in local field potentials recorded throughout the hippocampus and related structures during navigation, among other behavioral states (Vanderwolf, 1969; Buzsaki, 2002).

The possibility that hippocampal circuitry, and theta oscillations in particular, might be abnormal in the $5-\mathrm{HT}_{1 \mathrm{~A}} \mathrm{R}$ knockouts is also suggested by the finding that anxiolytics, including benzodiazepines and $5-\mathrm{HT}_{1 \mathrm{~A}} \mathrm{R}$ agonists, decrease the propensity of the hippocampus to oscillate in the theta-frequency range (McNaughton et al., 1977; Zhu and McNaughton, 1994, 1995). These data suggest the hypothesis that theta-frequency oscilla- 
tions might be increased in magnitude in $5-\mathrm{HT}_{1 \mathrm{~A}} \mathrm{R}$ knock-out mice. The present study tests this hypothesis by comparing local field potential recordings in awake, behaving knock-out and wild-type littermates. Findings reported here show that the knock-outs indeed have an increased magnitude of thetafrequency oscillations while they explore an elevated plus maze. Theta magnitude correlates with fraction open time, an anxietyrelated behavioral variable (Pellow et al., 1985), and the increase in theta magnitude seen in the knock-outs persists across multiple exposures to the elevated plus maze, demonstrating that the difference is not attributable to novelty. These data raise the possibility that the hippocampus, and theta-frequency oscillations in particular, might play a role in the expression of anxiety.

\section{Materials and Methods}

Animals. 5- $\mathrm{HT}_{1 \mathrm{~A}} \mathrm{R}$ knock-out mice were generated as described previously (Ramboz et al., 1998). All experiments were conducted blind to genotype on knock-out and wild-type littermates derived from heterozygote breeding pairs on a $129 / \mathrm{Sv}$ genetic background. The procedures described herein were conducted in accordance with National Institutes of Health regulations and approved by the Institutional Animal Care and Use Committees of Columbia University and the New York State Psychiatric Institute.

Surgical implantation. Custom microdrives were adapted from the method of Kentros et al. (2004) and were constructed using a Teflon platform suspended via stainless steel machine screws over Teflon nuts. The platform carried a 16-channel electrode interface board (Neuralynx, Tucson, AZ), and a 25 ga stainless steel cannula, through which were threaded two $75 \mu \mathrm{m}$ Teflon-coated, blunt-cut tungsten wire electrodes. Two 30 ga solid-core wires were connected directly to the interface board to serve as reference and ground.

Surgery was conducted on animals aged 3-6 months. Animals were anesthetized with ketamine/xylazine (100 and $7 \mathrm{mg} / \mathrm{kg}$, in saline) and placed in a stereotaxic frame. Body temperature was maintained by a temperature controller-regulated heating pad (Frederick Haer Company, Bowdoinham, ME). The skin overlying the dorsal surface of the skull was resected, and a $1.0 \mathrm{~mm}$ borehole was made stereotactically over the approximate position of the dorsal CA1 region of the hippocampus (coordinates: anteroposterior, $-1.8 \mathrm{~mm}$; lateromedial, $1.6 \mathrm{~mm}$ relative to bregma). Screw electrodes were implanted over the opposite frontal cortex (for reference) and cerebellum (for ground). The microdrive was then lowered into the borehole so that the tip rested $0.5 \mathrm{~mm}$ below the dural surface. The borehole was covered with warm petroleum jelly mixed with triple antibiotic ointment. The screw electrodes and microdrive were anchored to the skull with methyl methacrylate (Grip Cement; Dentsply, Milford, DE). Animals were then removed from the stereotaxic device and kept warm until recovered from anesthesia. Animals were allowed to recover for at least 1 week, until they returned to their preoperative weight (plus the weight of the installed microdrive, $\sim 2.5 \mathrm{~g}$ ).

Electrophysiological recordings. Animals were attached to a unitary gain head-stage preamplifier (HS-16; Neuralynx) via a cable suspended on a pulley so as not to add any weight to the animal's head. Signals were amplified and bandpass filtered $(1-9000 \mathrm{~Hz})$ by a Lynx 8 programmable amplifier (Neuralynx) and acquired at $2000 \mathrm{~Hz}$ on a personal computer running Cheetah data acquisition software (Neuralynx). The animal's position was obtained by overhead video tracking of two light-emitting diodes affixed to the head stage. Position was measured at $30 \mathrm{~Hz}$.

Locating the pyramidal layer. After recovery, animals were food deprived to $\sim 80 \%$ of bodyweight (preoperative plus microdrive weight). One to two times daily, animals were habituated to a familiar environment: a $35-\mathrm{cm}$-diameter circular arena constructed of wooden walls and a replaceable paper floor. Dim lighting (10 lux) was used as animals foraged for $20 \mathrm{mg}$ pellets dropped from a dispenser above the arena every $60 \mathrm{~s}$. Animals typically ate most of the pellets during this foraging period by the second exposure, and there was no difference by genotype in terms of the amount of pellets eaten. Animals received an additional ration of food sufficient to maintain their body weight on being returned to their home cages.
Between exposures to the familiar environment, local field potential recordings were obtained from both implanted electrodes while the animal rested in its home cage. Slow-wave $(1-4 \mathrm{~Hz})$ sleep periods were recognized by examining the broadband-filtered recordings on-line as by Buhl et al. (2003) and were easily distinguished from the periods of more regular, rapid theta activity that accompanied movement. The signal was simultaneously bandpass filtered at $100-350 \mathrm{~Hz}$ to search for ripple oscillations. The electrodes were advanced in $40 \mu \mathrm{m}$ increments by turning each of the three screws supporting the microdrive one-eighth turn until ripples were first detected on either electrode. Subsequently, the microdrive was advanced in $20 \mu \mathrm{m}$ ( $1 / 16$ turn) increments until the magnitude of the ripples did not increase further. Once the pyramidal layer was located and the animals were exposed to at least five foraging sessions in the familiar environment, animals were returned to their home cages overnight before testing in the elevated plus maze.

Recording sessions. Recordings were obtained during a 10 min exposure to the elevated plus maze the next morning. The elevated plus maze was constructed of wood painted black and consisted of four arms, each $7.6 \mathrm{~cm}$ wide and $28 \mathrm{~cm}$ long, elevated $31 \mathrm{~cm}$ above the floor. Two of the arms were enclosed by $15-\mathrm{cm}$-high walls, whereas two were open except for a 1-cm-high lip at the edge. [This precise maze has been used in previous experiments to demonstrate increased anxiety in $5-\mathrm{HT}_{1 \mathrm{~A}} \mathrm{R}$ knock-outs (Gross et al., 2002).] Light levels were raised to 110 lux for the elevated plus maze exposures.

Animals were then removed from the elevated plus maze, allowed to rest in their home cages for $30 \mathrm{~min}$, and then placed in the familiar environment to forage for $30 \mathrm{~min}$ under low-light conditions. Path length, speed, fraction time spent, and fraction path length in the center did not differ by genotype in the familiar environment under these conditions. Field potential recordings were obtained from the entire $30 \mathrm{~min}$ session; data from just the first $10 \mathrm{~min}$ are presented here for equivalence with the $10 \mathrm{~min}$ exposure to the elevated plus maze, although the results are indistinguishable from those obtained from the entire session.

After the familiar recording sessions, animals were placed in their home cages, fed, and rested for $30 \mathrm{~min}$. The animals were then connected to the recording apparatus while still in the home cage, under low-light conditions (10 lux). Recordings were obtained while the animal rested motionless within the cage. Sleep periods were marked by an observer monitoring both the broadband (1-9000 Hz) and ripple-filtered (100$350 \mathrm{~Hz}$ ) signals, as by Buhl et al. (2003). Slow-wave sleep periods were easily recognized, with $1-4 \mathrm{~Hz}$ activity predominating in the broadband signal and ripples clearly seen in the filtered signal. Periods of rapid eye movement (REM) sleep were also easily recognized, as the animal remained motionless, but theta activity (typically very regular at $\sim 6 \mathrm{~Hz}$ ) dominated the broadband signal and ripples were absent. These markings were later used to segment the sleep sessions. Transitions between phases of sleep or between sleep and waking were discarded. Power spectra from REM periods yielded a sharp theta peak, whereas power spectra from slow-wave sleep periods yielded $1-4$ and $150 \mathrm{~Hz}$ peaks but no peak in the theta range (see Fig. 8 and data not shown). The above procedures (elevated plus maze, familiar and sleep sessions) were repeated each morning for $3 \mathrm{~d}$.

Depth series. For the depth series shown in Figure $1 A$, a single wildtype animal was allowed to recover after surgery and then was food deprived to $80 \%$ of bodyweight. The animal was exposed five times to the familiar environment, and then a depth series was initiated. The electrodes were advanced three to four times daily in $40 \mu \mathrm{m}$ (one-eighth turn) increments. Recordings were obtained during foraging in a familiar environment and during slow-wave sleep in the home cage at each increment.

Data analysis. Records were imported into Matlab (MathWorks, Natick, MA) for analysis. For theta analysis, the records were decimated to $400 \mathrm{~Hz}$. Head speed and location were determined for each position record $(30 \mathrm{~Hz})$; speed was smoothed with a rectangular window of 10 samples $(0.33$ s). For overall power (see Figs. 1, 2, 6), a single power spectrum was calculated using the multi-taper method for the entire 10 min local field potential record. Mean power spectra were then calculated by genotype. For analysis of power by speed or location (see Figs. 3, 5), field potential records from each session were divided into short seg- 
ments (at least $0.25 \mathrm{~s}$ and averaging $0.75-1 \mathrm{~s}$ per segment), during which the animal's speed or location fell within the assigned boundaries (for speed, $0-4,4-8,8-12,12-16,16-20$, and $>20 \mathrm{~cm} / \mathrm{s}$; for location, center, open arms, or closed arms). This procedure eliminated potential confounds, such as side-to-side head movements and deceleration, known to affect theta magnitude (Wyble et al., 2004). Distributions of segment lengths did not different by genotype. These segments were then concatenated, and power spectra were calculated for each speed range or location using the multi-taper method. Segments $<0.25 \mathrm{~s}$ of constant speed or location were discarded. Theta power was calculated by summing the area under the curve of the power spectra from 4 to $12 \mathrm{~Hz}$. Repeated-measures ANOVAs were performed using JMP (SAS Institute, Cary, NC) to test for differences in mean theta power across genotype, speed, and location.

Theta maps (see Fig. 4) were produced by first calculating theta power for a $0.5 \mathrm{~s}$ window around each position record. Theta power for a given position was then calculated by averaging the power for all visits to a given position. Maps did not differ when a smaller window was used to calculate theta $(0.25 \mathrm{~s})$. Speed maps were produced by averaging the speed (smoothed as described above) for all visits to a given position.

Ripples were analyzed by using the full records as acquired at $2000 \mathrm{~Hz}$. Power spectra for Figure $8 \mathrm{~A}$ were computed on unfiltered segments of local field potential data taken during short-wave sleep epochs, typically tens of seconds in length, identified as described above. To measure ripple size, individual ripples were isolated from these segments by filtering the records at $100-350 \mathrm{~Hz}$ and identifying samples with values $>7$ SDs from the mean, as by Buzsaki et al. (2003). Mean peak-to-trough amplitude was determined for each animal by averaging the peak-totrough amplitudes of each of the isolated ripples, and the grand means by genotype were compared (see Fig. 8). Power spectra for gamma were calculated from the decimated records ( $400 \mathrm{~Hz}$ sampling rate); the gam$\mathrm{ma} /$ theta phase relationship was calculated using a Hilbert transform as by Buzsaki et al. (2003).

Factor analysis was conducted using the principle components function of JMP5.1 (SAS Institute). A varimax factor rotation was conducted on all factors with eigenvalues $>1$. All factor loadings $>0.4$ are displayed in Table 1. Power analyses on repeated-measures ANOVA were performed according to the methods of Murphy and Myors (1998).

Histology. After completion of recordings, electrolytic lesions were placed at the recording site by passing a small current through the recording electrode. Animals were then anesthetized with a lethal dose of ketamine and perfused with 10\% Formalin. Sections, $40 \mu \mathrm{m}$ thick, through the hippocampus were stained with cresyl fast violet and examined for the location of the lesions.

\section{Results}

The magnitude of theta oscillations varies several-fold throughout the depth of the hippocampus (Fig. 1A) (Buzsaki, 2002). To compare theta power across animals, therefore, a reliable indicator of depth within the hippocampus is crucial. The presence of high-frequency ripple oscillations was used to ensure that the tip of the recording electrode lay within the pyramidal layer, permitting accurate measurement of absolute theta power. Ripples are short, 25-75 ms waves with a peak frequency of $\sim 150 \mathrm{~Hz}$ in mice (Buzsaki et al., 2003), resulting from activation of CA1 pyramidal neurons by inputs from CA3 (Ylinen et al., 1995; Csicsvari et al., 1999).

5- $\mathrm{HT}_{1 \mathrm{~A}} \mathrm{R}$ knock-out mice and littermate controls were implanted with tungsten microelectrodes in the cortex immediately above dorsal CA1, and animals were allowed to recover for a period of 7-10 d. The animals were then food deprived and exposed to a cylindrical, 35-cm-diameter "familiar environment" while tethered to the recording apparatus. The animals foraged for food pellets in the familiar environment for $30 \mathrm{~min}$ one to two times daily and a minimum of five times overall, to habituate to the environment, tethering, and handling. Between exposures to the familiar environment, mice were returned to their home cage,

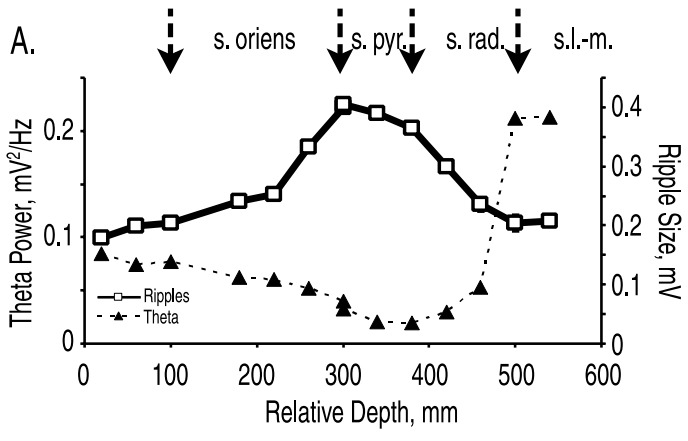

B.

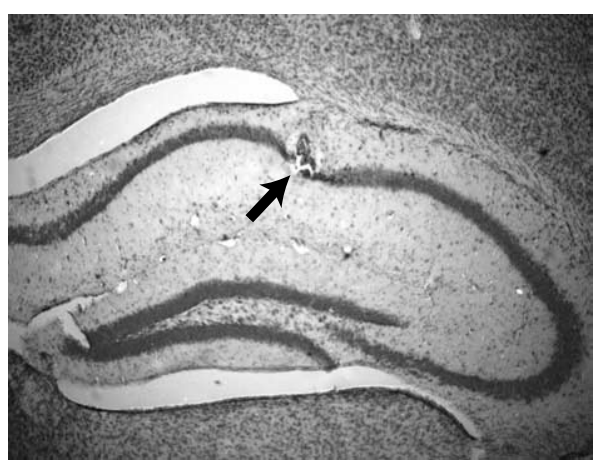

Figure 1. Ripples mark the pyramidal layer. $\boldsymbol{A}$, Depth profiles of ripple size (open squares) and theta power (filled triangles) through the CA1 region of the hippocampus. Depth is relative to initial electrode position. Arrows above indicated estimated location of boundaries between stratum oriens (s. oriens), pyramidale (s. pyr.), radiatum (s. rad.), and lacunosum moleculare (s.l.-m.). B, Nissl-stained section from the hippocampus of a mouse lesioned after completing the experiment. Arrow indicates location of lesion within the pyramidal layer.

and local field potential recordings were made during slow-wave sleep. The electrode was advanced in $20-40 \mu \mathrm{m}$ intervals, to a maximum of $320 \mu \mathrm{m} / \mathrm{d}$, until ripples were clearly visible and did not increase further in magnitude. The experimental protocol began the day after the pyramidal layer was located or the day after the fifth exposure to the familiar environment, whichever came later. This procedure reliably located the pyramidal layer as revealed by electrolytic lesions placed at the conclusion of the recordings (Fig. 1B). All experiments were done blind to genotype.

\section{$5-\mathrm{HT}_{1 \mathrm{~A}} \mathrm{R}$ knock-outs have increased theta in the elevated plus maze}

Once the pyramidal layer was located, field potential recordings were obtained while the animal explored an elevated plus maze, foraged in the familiar environment, and slept in its home cage. In both wild type and $5-\mathrm{HT}_{1 \mathrm{~A}} \mathrm{R}$ knock-outs, field potential recordings contained prominent oscillations; power spectra obtained from each condition revealed a distinct peak in the previously reported range of theta-frequency oscillations (Fig. 2) (Buzsaki et al., 2003). Comparing the power spectra across genotypes, it appeared that the theta peak was higher in knock-outs than in wild types in the elevated plus maze.

To quantify this difference, each recording was divided into segments in which the animal was moving at a given speed, because theta magnitude is known to increase with increasing speed (Vanderwolf, 1969). Spectra were then computed on these speeddivided records, and the area under the curve within the theta range $(4-12 \mathrm{~Hz})$ was summed. In recordings made while the animals explored the elevated plus maze, theta power in the knock-outs was consistently higher than in wild types, regardless 

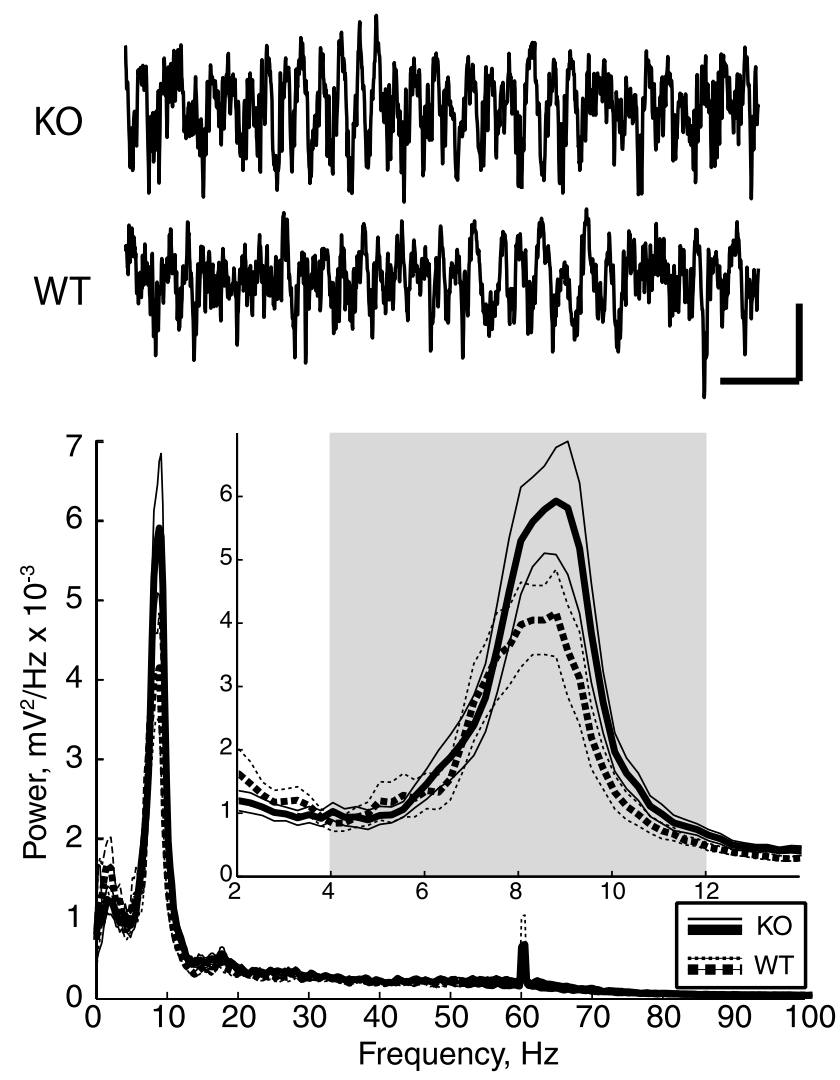

Figure 2. Top, Representative local field potential recordings from knock-out (KO) and wildtype (WT) mice navigating an elevated plus maze. Four seconds of data are shown; theta power is 0.081 and 0.051 for the knock-out and wild-type segments, respectively. Calibration: $0.5 \mathrm{mV}$, 0.5 s. Bottom, Averaged power spectra from all $5-\mathrm{HT}_{1 \mathrm{~A}} \mathrm{R}$ knock-out (solid lines) and wild-type (dashed lines) mice during exposure to an elevated plus maze. Inset, Expansion of power spectra in theta range. Thin lines are \pm SEM. $n=14$ animals per group.
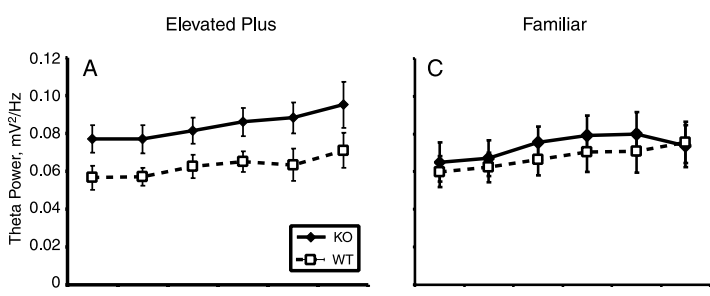

REM
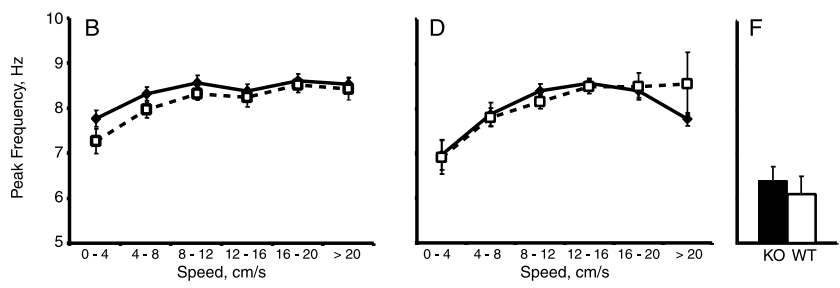

Figure 3. Theta power is increased in $5-\mathrm{HT}_{1 \mathrm{~A}} \mathrm{R}$ knock-out mice during exposure to the elevated plus maze. Mean \pm SEM of theta power $(\boldsymbol{A}, \boldsymbol{C}, \boldsymbol{E})$ and peak frequency $(\boldsymbol{B}, \boldsymbol{D}, \boldsymbol{F})$ during exposure to the elevated plus maze $(\boldsymbol{A}, \boldsymbol{B})$, a familiar environment $(\boldsymbol{C}, \boldsymbol{D})$, and during REM sleep in the home cage $(\boldsymbol{E}, \boldsymbol{F})$. For the elevated plus maze and familiar environment, power is calculated separately for epochs divided by the speed of the animal. Filled diamonds, $5-\mathrm{HT}_{1 \mathrm{~A}} \mathrm{R}$ knockouts; open squares, wild types. $n=10-14$ animals per group.

of the speed at which the animals traveled $(p<0.03$ by repeatedmeasures ANOVA) (Fig. 3A). The correlation of power with speed, although small, was present in both genotypes $(p<0.005$

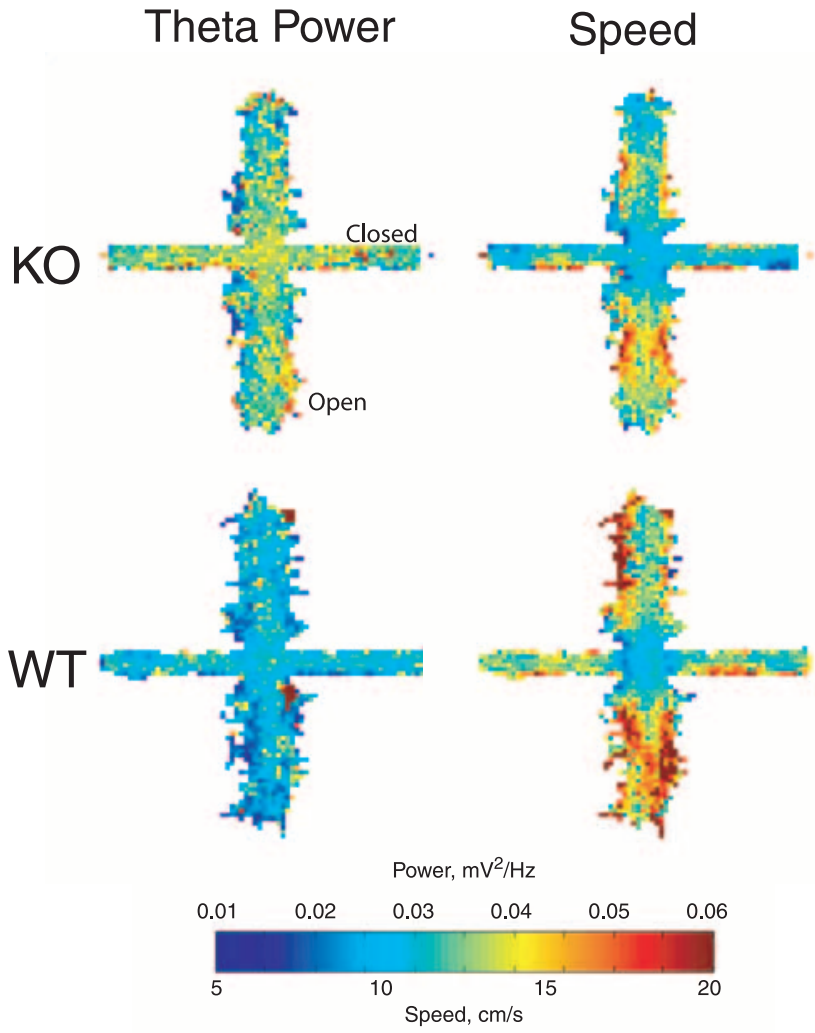

Figure 4. Theta power is increased in $5-\mathrm{HT}_{1 \mathrm{~A}} \mathrm{R}$ knock-outs throughout the elevated plus maze. Maps of theta power (left) and speed (right) averaged by genotype. $n=14$ animals per group. Open arms are arranged vertically; closed arms are arranged horizontally. K0, Knockouts; WT, wild types.

for the main effect of speed; $p=0.9$ for speed $\times$ genotype interaction). The increase in theta power was likely attributable to increased amplitude of the oscillations as opposed to increased regularity because the width of the power spectra did not change (Fig. 2 and data not shown). Moreover, mean peak-to-trough amplitude of theta-filtered field potentials was similarly affected by genotype, although there were no differences in the interpeak interval distributions or autocorrelation functions (supplemental Fig. S1, available at www.jneurosci.org as supplemental material).

In the familiar environment and during REM sleep, the effect of genotype was minimal and not statistically significant $(p=$ 0.56 and 0.52 by repeated-measures ANOVA and $t$ test, respectively; genotype accounted for only $2.2 \%$ of the variance in the familiar environment compared with $24.9 \%$ in the elevated plus maze) (Fig. 3C,E). Indeed, when divided by speed, the tendency for knock-outs to have increased theta power in the familiar environment was so small that a sample size of 380 per group would be required to detect the difference with a power of 0.8. In all three conditions, theta frequency was not affected by genotype (Fig. $3 B, D, F$ ).

\section{Theta power is increased throughout the elevated plus maze}

To determine whether theta power is modulated by location with the maze, theta power was calculated for a $0.5 \mathrm{~s}$ window surrounding each position measurement. This continuous record of theta power was used to construct a map of theta power by position for each animal; the maps were then averaged across animals by genotype. In Figure 4, these averaged maps of theta power are shown along with similarly averaged maps of head speed. The 

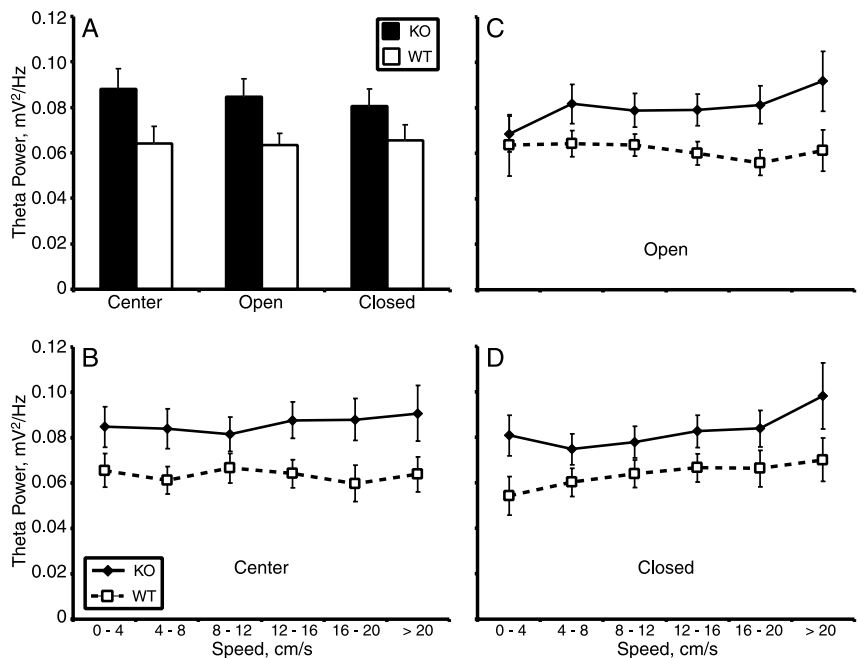

Figure 5. $5-\mathrm{HT}_{1 \mathrm{~A}} \mathrm{R}$ knock-outs have increased theta in the elevated plus maze regardless of location or speed. Theta power by location $(\boldsymbol{A})$ or by speed within location $(\boldsymbol{B}-\boldsymbol{D})$. Filled bars, $5-\mathrm{HT}_{1 \mathrm{~A}} \mathrm{R}$ knock-outs (KO); open bars, wild types (WT). Other conventions as in Figure 3. $n=$ 8-14 animals per group.

overall difference in power between knock-outs and wild types is immediately apparent from the theta maps; throughout the maze, theta power was generally higher in the knock-outs than in the wild types (Fig. 4A,B). The lack of correlation between the power and speed maps, found in both genotypes, is also potentially interesting given the finding that, under some conditions, speed and theta have been related (Vanderwolf, 1969; Nitz and McNaughton, 1999). Power was mostly uniform throughout the maze, whereas speed was lowest in the center and higher on the open arms. The effect of genotype on theta power appears generally larger than the effect of speed.

The spatial distribution of theta power was quantified by dividing the local field potential recordings by location and calculating theta power separately for the center, the open arms, and the closed arms. Regardless of location, power was greater in knock-outs than in wild-type animals ( $p<0.05$ by repeatedmeasures ANOVA) (Fig. 5A). To rule out the possibility that speed differences in each compartment accounted for the genotype differences, the records were then further subdivided by speed. The knock-out/wild-type differences in theta power were present regardless of speed in each location (Fig. $5 B-D$ ). Notably, theta power did not vary significantly by location within the elevated plus maze (compare individual speeds in Fig. $5 B-D$ ), nor was there evidence of a genotype by location interaction effect. There were also no statistically significant effects of genotype on speed.

\section{Theta power correlates with anxiety-related behavior}

The physiology cohort was too small to detect behavioral differences by genotype; to replicate the effect seen in the initial characterization of these knock-outs by Ramboz et al. (1998) with power of 0.80 requires 25-30 animals per group. Moreover, these animals were by necessity handled on a daily basis, a manipulation that decreases anxiety-like behavior in the elevated plus maze (Rodgers and Dalvi, 1997) and might make the behavioral differences between knock-outs and wild types more difficult to measure. Accordingly, no significant genotype differences were found in the two traditional measures of anxiety, fraction open arm entries (number of open entries/[number of open + number of closed entries]) or fraction time in the open arms (open time/
Table 1. Factor analysis

\begin{tabular}{|c|c|c|c|c|}
\hline Factors & 1 & 2 & 3 & 4 \\
\hline Fraction open entries & -0.9 & & & \\
\hline Open time & -0.9 & & & \\
\hline Open entries & -0.9 & & & \\
\hline Fraction open time & -0.4 & & -0.6 & \\
\hline Closed entries & & 0.9 & & \\
\hline Total entries & & 0.8 & & \\
\hline Closed time & & 0.8 & & \\
\hline Center time & & -0.7 & -0.5 & \\
\hline Theta power & & & 0.8 & \\
\hline Genotype & & & 0.7 & \\
\hline Dips & & & & 0.9 \\
\hline
\end{tabular}

Factor analysis of behavior and theta power in the elevated plus maze. All factor loadings $>0.4$ are shown.

[open + closed time]). Nonetheless, $5-\mathrm{HT}_{1 \mathrm{~A}} \mathrm{R}$ knock-outs did spend significantly less time in the center of the maze (mean \pm SEM, $237 \pm 29$ and $354 \pm 36$ for knock-outs and wild types, respectively; $p=0.015$ by $t$ test). In a factor analysis, Ramboz et al. (1998) found center time to segregate with genotype and other anxiety-related variables.

To determine whether the differences in the knock-outs' behavior were attributable to anxiety-related factors, and what relationship these factors might have to theta power, a factor analysis was performed on the combined behavioral and physiological data. To prevent spurious correlations attributable to speed effects, theta power measurements from the middle speed range $(8-12 \mathrm{~cm} / \mathrm{s})$ were used, although similar results were obtained with other speed ranges. Four factors were identified with eigenvalues $>1$, accounting for $82 \%$ of the total variance. Loadings $>0.4$ are shown for each of these factors in Table 1 . Factor 1 is clearly an anxiety-related factor, reflecting correlations between fraction open entries and fraction open time. Factor 2 probably reflects exploratory activity, because the numbers of total and closed entries load onto this factor. Dips, an exploration and anxiety-associated variable, loads separately onto factor 4 . Accounting for $\sim 16 \%$ of the total variance, factor 3 captures the correlation between fraction open time, center time, genotype, and theta power. This factor indicated that those animals with high theta power tended to spend less time in the open arms (relative to the closed arms), tended to spend less time in the center, and tended to be knock-outs.

Reflecting the strong influence of this factor, overall theta power in the elevated plus maze correlated with fraction open time (Fig. 6A). Those animals that spent less time in the open arms, indicative of greater anxiety, had higher theta power, regardless of genotype $\left(p<0.001 ; r^{2}=0.25\right.$ by ANCOVA; $p>0.2$ for an interaction with genotype). This relationship was not an artifact attributable to differences in speed, because correlations between fraction open time and theta power at any given speed were also significant $(p=0.02,0.05,0.03,0.05,0.03$, and 0.02 for speeds $0-4,4-8,8-12,12-16,16-20$, and $>20 \mathrm{~cm} / \mathrm{s}$, respectively). The behavior, factor analysis, and correlation of theta power with fraction open time are all consistent with an association between the knock-out genotype, higher theta power, and higher levels of anxiety-related behavior.

Anxiety-related behavioral measures within the elevated plus maze do not habituate on repeated exposure, allowing the effects of novelty and anxiety to be differentiated (File et al., 1993; Rodgers and Shepherd, 1993; Fernandes and File, 1996; Holmes and Rodgers, 1998). If elevated theta power accompanies increased anxiety, the genotype difference in theta power should persist on multiple exposures to the elevated plus maze. To test this possi- 

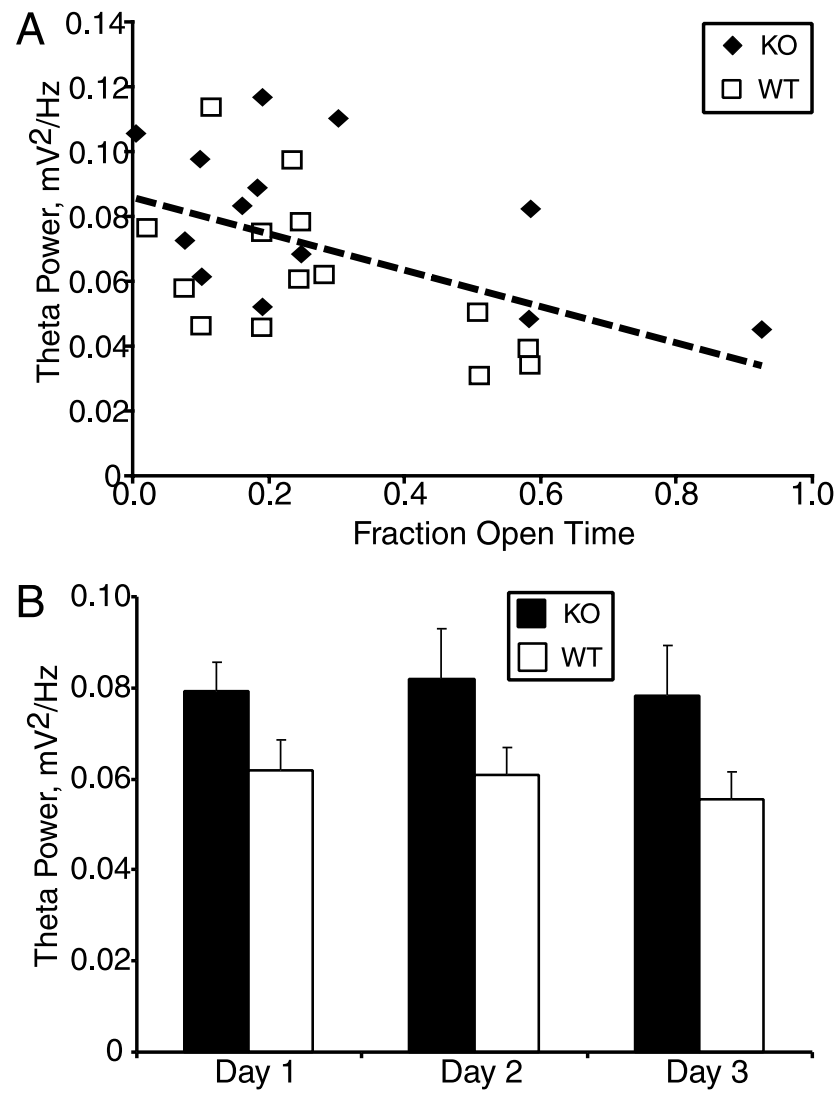

Figure 6. Theta power correlates with anxiety-like behavior. $\boldsymbol{A}$, Linear regression (dashed line) of theta power on fraction open time in the elevated plus maze. $\boldsymbol{B}$, Theta power in knockouts $(K 0)$ and wild types (WT) during three successive daily exposures to the elevated plus maze. Conventions as in Figure $5 . n=8-14$ animals per group.

bility, each animal was exposed to the elevated plus maze once daily for $3 \mathrm{~d}$. Overall theta power was increased between groups across all $3 \mathrm{~d}$ of the task $(p<0.05$ by repeated-measures ANOVA) (Fig. $6 B)$ with no effect of day $(p=0.64)$. This result was again not attributable to differences in speed, because theta power was elevated regardless of speed on day $3(p<0.05$ for the main effect of genotype; data not shown). The persistence of the elevation in theta magnitude argues that the increase is related to anxiety rather than novelty.

\section{Mice tend to avoid areas of the maze where theta power is highest}

The data described above suggest a link between theta oscillations and the anxiety-like state induced by exposure to the elevated plus maze. Although stress hormone and ethological studies demonstrate increased anxiety-like behavior throughout the maze, animals appear to be more anxious in the open arms than in the closed arms (Pellow et al., 1985). One might therefore expect to find increased theta power in the open arms; such within-maze modulation was not seen in the averaged data (Figs. $4,5)$. Variability in both behavior and theta power, however, may have obscured small intramaze differences in theta when averaged across animals. To explore this issue more precisely, correlations between intramaze differences in theta power and relevant behavior variables were examined. Because center time and fraction open time were shown to load with theta power and genotype by factor analysis, these variables were selected for additional study. Intramaze modulation of theta power was ex-

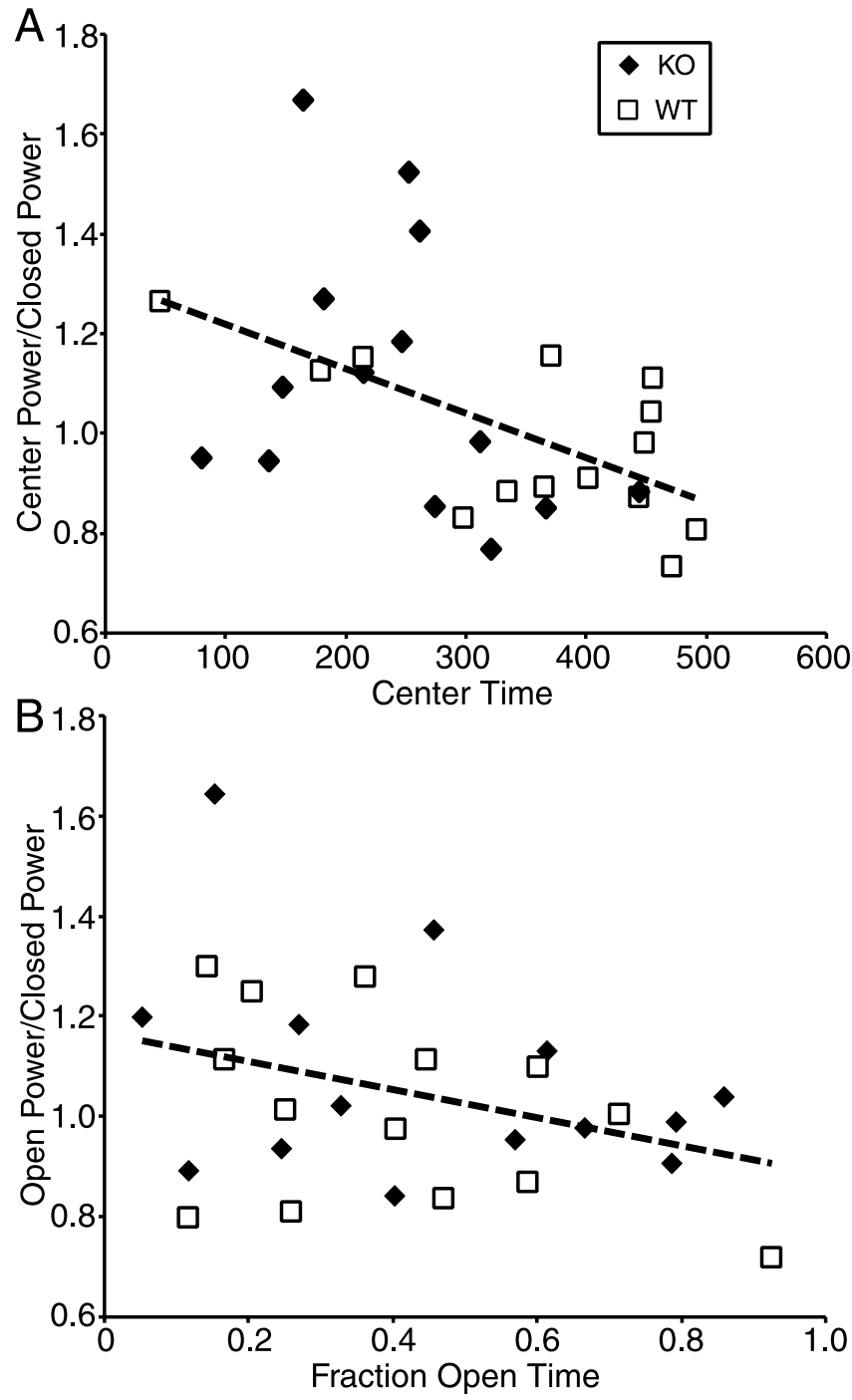

Figure 7. Mice tend to avoid areas of the elevated plus maze where theta power is greatest. $\boldsymbol{A}$, Linear regression (dashed line) of the ratio of theta power in the center to power in the closed arm, on time spent in the center of the maze. $\boldsymbol{B}$, Linear regression (dashed line) of the ratio of theta power in the open arm to power in the closed arm, on fraction time spent in the open arm. KO, Knock-outs; WT, wild types.

pressed as a ratio of power in the center or open arms to power in the closed arms; these ratios also have the virtue of controlling for interanimal variability in theta power. The time spent in the center of the maze correlated inversely with the ratio of power in the center to power in the closed arms $\left(r^{2}=0.26 ; p<0.03\right.$ by ANCOVA; no interaction with genotype) (Fig. $7 A$ ). The correlation was only moderately robust to speed, however, with $p$ values of $0.3,0.003,0.10,0.4,0.09$, and 0.6 for $0-4,4-8,8-12,12-16$, $16-20$, and $>20 \mathrm{~cm} / \mathrm{s}$. A trend toward a similar correlation was seen between the ratio of power in the open arms to power in the closed arms and fraction open time $\left(r^{2}=0.12 ; p=0.07\right.$ by ANCOVA; no interaction with genotype) (Fig. 7B). These correlations, although weak overall, suggest the possibility that higher theta power in a given compartment of the maze is associated with avoidance of that compartment.

Effects of the knock-out on fast hippocampal oscillations The effect of 5- $\mathrm{HT}_{1 \mathrm{~A}} \mathrm{R}$ deletion on high-frequency ripple oscillations during slow-wave sleep epochs was also examined. Power 

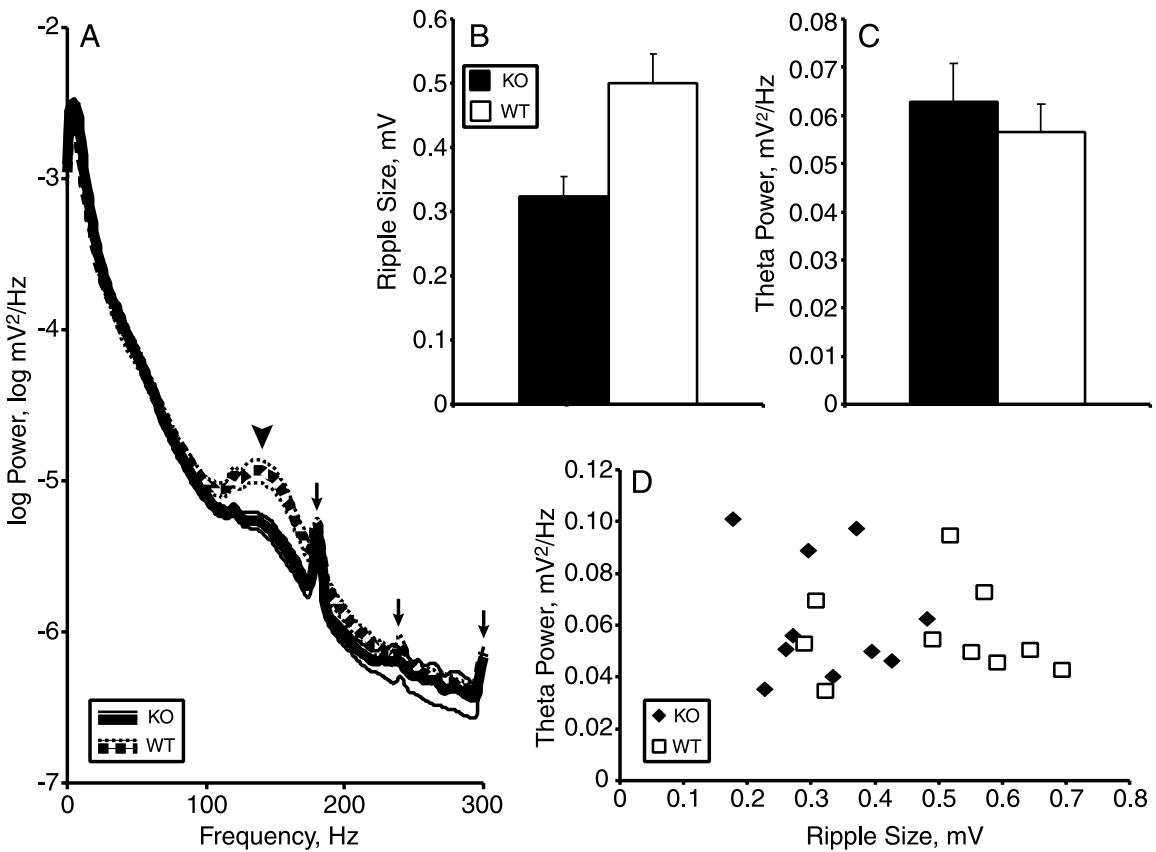

Figure 8. Ripples are decreased in size in 5- $\mathrm{HT}_{1 \mathrm{~A}} \mathrm{R}$ knock-out mice. $A$, Power spectra of $5-\mathrm{HT}_{1 \mathrm{~A}} \mathrm{R}$ knock-out (K0) and wild-type (WT) mice during slow-wave sleep. Arrowhead indicates ripple peak. Arrows mark third, fourth, and fifth harmonic of $60 \mathrm{~Hz}$ noise. $\boldsymbol{B}$, Mean peak-to-trough amplitude of isolated ripples from knock-outs and wild types. $\boldsymbol{C}$, Theta power during REM sleep from the same recording sessions as in $\boldsymbol{A}$ and $\boldsymbol{B}$. D, Plot of REM theta power versus ripple size. $n=10$ animals per group.

9A, C). Gamma oscillations have a particular phase relationship with theta oscillations that depends on recording depth; gamma amplitude peaks just after the theta peak when the recording electrode is positioned within the pyramidal layer (Buzsaki et al., 2003). In our recordings, both genotypes had similar theta/gamma phase relationships (Fig. 9B,D). Peaks in gamma amplitude relative to theta phase were indistinguishable in the two genotypes $\left(193.6 \pm 2.3^{\circ}\right.$ and $195.7 \pm 3.8^{\circ}$ for knock-outs and wild types, respectively, mean \pm SEM; $n=14$ per genotype).

\section{Discussion}

Mice lacking the $5-\mathrm{HT}_{1 \mathrm{~A}} \mathrm{R}$ have a robust phenotype of increased anxiety (Heisler et al., 1998; Parks et al., 1998; Ramboz et al., 1998). To identify the consequences of the gene deletion responsible for this phenotype, hippocampal activity was recorded from awake, behaving $5-\mathrm{HT}_{1 \mathrm{~A}} \mathrm{R}$ knockout mice. These mice exhibited a statedependent increase in the magnitude of hippocampal theta-frequency oscillations. These oscillations were increased in an anxiety-provoking environment, the elevated plus maze, but not in a familiar environment or during REM sleep. Theta

spectra computed from field potential recordings during these slow-wave sleep epochs revealed a peak at $\sim 150 \mathrm{~Hz}$ in both wildtype and knock-out mice (Fig. $8 \mathrm{~A}$ ), although the peak was markedly smaller in the knock-outs. A smaller peak in the power spectrum could be caused by less frequent or smaller ripples. To differentiate from these possibilities, 50-100 individual ripples were isolated from slow-wave sleep recordings from each animal, and mean peak-to-trough ripple amplitude was calculated (see Materials and Methods). Mean ripple amplitude was significantly higher for wild types than knock-outs ( $p<0.01$ by $t$ test) (Fig. $8 B)$. The frequency of identified ripple events did not differ by genotype (data not shown).

Of course, smaller ripples and higher theta power could be the result of experimental error if the recording electrode was not precisely positioned in the pyramidal layer in the knock-outs. Theta power measured during REM sleep epochs taken from the same recording sessions, however, did not differ by genotype, making this explanation unlikely (Fig. 8C). Moreover, there was no correlation between REM theta power and ripple size in either genotype (Fig. 8D), as would be expected if electrode position accounted for the variation in our measurements. Despite the genotype difference in ripple size, no significant correlation between ripple size and anxiety-related behavioral measures or theta power in the elevated plus maze was seen (data not shown), suggesting that these effects are related only in that they result from genetic ablation of the $5-\mathrm{HT}_{1 \mathrm{~A}} \mathrm{R}$.

As an additional control for proper electrode positioning, the relationship between gamma and theta activity during both elevated plus maze and familiar environment exposures was examined. Gamma oscillations are $40-100 \mathrm{~Hz}$ oscillations that are seen throughout the hippocampus, arising from synchronous activity in interneuron populations (Csicsvari et al., 2003; Mann and Paulsen, 2005). The magnitude of these oscillations did not differ between knock-outs and wild types in either environment (Fig. power was higher in those animals that showed higher levels of anxiety-related behavior, and the increase in theta power in the knock-outs persisted across multiple exposures to the elevated plus maze. Together, these results support the hypothesis that abnormal hippocampal activity may contribute to the anxietylike phenotype seen in the knock-outs, although alternative explanations must be considered.

\section{Theta oscillations and anxiety}

The idea that hippocampal theta oscillations play a role in anxiety is not new. Indeed, Gray and McNaughton (2000) have championed the hypothesis for the past two decades. The idea originated with the findings that lesions of the septohippocampal circuit responsible for driving theta oscillations disrupt anxiety-like behavior on such tasks as the open field, elevated plus maze, social interaction, light-dark, shock-probe burying, and hyponeophagia tests (Miller et al., 1986; Deacon et al., 2002; Degroot and Treit, 2003; Bannerman et al., 2004). Recent studies have generally shown that the anxiety phenotype arises specifically from ventral hippocampal lesions (Kjelstrup et al., 2002; Bannerman et al., 2003; McHugh et al., 2004). For technical reasons (it is difficult to reliably establish precise electrode localization in ventral hippocampal subregions in vivo), the current work was performed in dorsal hippocampus. The implications of the present findings for ventral hippocampal activity in the knock-outs are unknown, although theta oscillations remain highly coherent with distance, even across hemispheres (Bullock et al., 1990; Buzsaki, 2002; Buzsaki et al., 2003).

The behavioral differences seen between the knock-outs and wild types in the elevated plus maze in this study were subtle and did not include genotype differences in pharmacologically validated measures of anxiety-related behaviors (Pellow et al., 1985). This raises the possibility that the theta phenotype is related to 

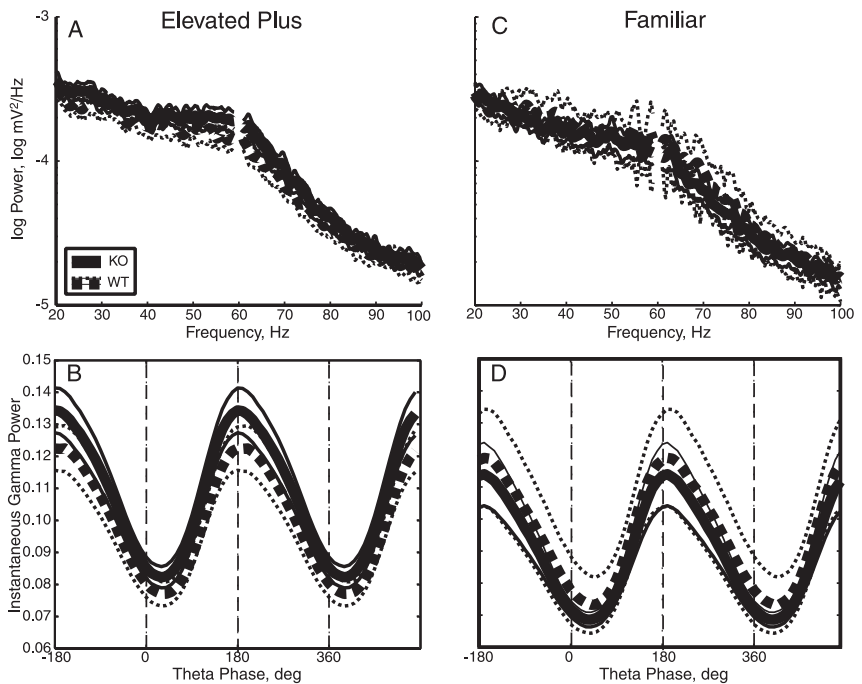

Figure 9. Gamma oscillations are not different by genotype. $A, C$, Power spectra during exposure to the elevated plus maze $(\boldsymbol{A})$ and the familiar environment $(\boldsymbol{C})$ expanded to highlight the gamma-frequency peak. $\boldsymbol{B}, \boldsymbol{D}$, Relationship between gamma oscillation amplitude and theta phase in the elevated plus maze $(\boldsymbol{B})$ and the familiar environment $(\boldsymbol{D}) . n=10-14$ animals per group. Conventions as in Figure 2. The $60 \mathrm{~Hz}$ artifact was removed in graphic. $\mathrm{KO}$, Knock-outs; WT, wild types.

other behavioral factors. For instance, $5-\mathrm{HT}_{1 \mathrm{~A}} \mathrm{R}$ knock-outs might have difficulty with the cognitive demands placed on them by environments such as the plus maze; deficits in spatial learning have been described in these mice (Sarnyai et al., 2000; Wolff et al., 2004). An intriguing possibility is that the theta oscillation abnormality contributes to both anxiety and spatial learning phenotypes, by altering a fundamental functional property of the hippocampus (Gray and McNaughton, 2000). Measuring theta oscillations during additional behavioral tasks would help differentiate from among these and other possibilities.

\section{How does 5- $\mathrm{HT}_{1 \mathrm{~A}} \mathrm{R}$ deficiency lead to altered hippocampal oscillations?}

From the limited literature on serotonergic effects on ripple oscillations, it seems likely that a decrease in ripple amplitude cannot be explained by a simple lack of the receptor in the adult. It is difficult to reconcile decreased ripple size, which suggests less excitation of CA1 pyramidal neurons (Csicsvari et al., 1999), with the absence of an inhibitory receptor. A recent report showed that pharmacological blockade of the $5-\mathrm{HT}_{1 \mathrm{~A}} \mathrm{R}$ with the specific antagonist WAY 100635 ( $\mathrm{N}$-[2-[4-(2-methoxyphenyl)-1-piperazinyl] ethyl $]-N$-(2-pyridinyl)cyclo-hexane carboxamide trihydrochloride) resulted in less frequent but normal-sized ripples (Ponomarenko et al., 2003) as opposed to the smaller but equally frequent ripples seen here in the knock-outs. These data argue that the change in ripple size seen in the knock-outs is likely attributable to an indirect effect of $5-\mathrm{HT}_{1 \mathrm{~A}} \mathrm{R}$ deletion, perhaps as a consequence of altered hippocampal development. Alternatively, serotonergic drugs are known to affect the sleep cycle, and 5- $\mathrm{HT}_{1 \mathrm{~A}} \mathrm{R}$ knock-out mice have altered sleep patterns (Boutrel et al., 2002; Monaca et al., 2003), suggesting that the less effective synchronization evident in smaller ripples could be a consequence of sleep disruption.

The story is also complex with regard to the better-studied theta oscillations. Serotonin is capable of modulating theta through several different receptors and pathways (Staubli and
Xu, 1995; Vertes and Kocsis, 1997; Kitchigina et al., 1999; Vertes et al., 2004). Manipulating serotonin levels with depleting agents or precursors suggests that serotonin may enhance theta, perhaps specifically atropine-resistant "type 1" theta associated with exploratory behavior (Vanderwolf and Baker, 1986; Robertson et al., 1991). (The theta oscillations measured here are likely type 1 , although no pharmacological dissection was performed.) However, lesioning or silencing the serotonergic raphe nuclei enhances theta, suggesting that serotonin normally suppresses theta oscillations (Maru et al., 1979; Vertes et al., 1994; Marrosu et al., 1996; Nitz and McNaughton, 1999). The suppressive effects of serotonin on theta are likely to be mediated, at least in part, through hippocampal 5- $\mathrm{HT}_{1 \mathrm{~A}} \mathrm{Rs}$, because direct hippocampal injection of $5-\mathrm{HT}_{1 \mathrm{~A}} \mathrm{R}$ agonists decreases theta power (Hirose et al., 1990). Such experiments suggest that the lack of the $5-\mathrm{HT}_{1 \mathrm{~A}} \mathrm{R}$ in the adult knock-out might prevent the normal suppression of theta power by serotonin.

This suggestion is not straightforwardly compatible with the state dependence of the theta increase seen in the knock-outs. To explain the finding that theta is only increased in the elevated plus maze, one would have to assert that serotonergic neurons are significantly active only in this environment. A state-specific increase in serotonin activity, acting on a hippocampus lacking the inhibitory $5-\mathrm{HT}_{1 \mathrm{~A}} \mathrm{R}$, would then fail to suppress theta in the knock-outs. The evidence for serotonergic activation during exposure to stressful or anxiety-provoking situations is mixed (Silveira et al., 1993; Jacobs and Fornal, 1997; Voigt et al., 1999; Rex et al., 2003). Microdialysis experiments in $5-\mathrm{HT}_{1 \mathrm{~A}} \mathrm{R}$ knock-outs are also inconclusive; exposure to an anxiety-provoking novel open field increases frontal cortical but not hippocampal serotonin release in knock-outs and wild types (Parsons et al., 2001).

An alternative hypothesis for the state-dependent increase in theta magnitude is that $5-\mathrm{HT}_{1 \mathrm{~A}} \mathrm{R}$ deficiency during development results in a fundamental alteration in the circuitry of the hippocampus; this hypothetical circuit alteration would affect regulation by serotonin or other processes active in anxietyprovoking situations (Gross et al., 2002). A number of studies implicate serotonin in the development of the hippocampus, including regulation of neurite outgrowth and synaptogenesis (Azmitia and Whitaker-Azmitia, 1997; Sodhi and Sanders-Bush, 2004). We have shown recently an increase in dendritic branching, dendritic length, and total number of spines in the proximal apical dendrites of CA1 pyramidal neurons in $5-\mathrm{HT}_{1 \mathrm{~A}} \mathrm{R}$ knockouts (J. E. Monckton, K. Klemenhagen, J. A. Gordon, C. Gross, R. Meylan, E. Prolong, R. Hen, and J.-P. Hornung, unpublished observation). These morphological changes are accompanied by an apparent increase in synaptic efficacy of the CA3 inputs onto these dendrites. Synaptic currents induced by these very inputs form part of the driving force of theta oscillations (Buzsaki, 2002). Although the CA3 inputs comprise a source that can act independently from the sources measured in the pyramidal layer (Kocsis et al., 1999), it is conceivable that the morphological and physiological changes seen at the level of the CA1 pyramidal neurons are related to the changes in hippocampal oscillations observed in vivo.

\section{Functional significance of increased theta oscillations}

Several roles for theta oscillations in hippocampal function have been proposed, most pertaining to models of synaptic plasticitybased learning (Huerta and Lisman, 1995; Hyman et al., 2003). Variation in the amplitude of theta oscillations might therefore alter plasticity. Some have argued that temporal encoding using the variable timing of firing of a hippocampal cell with relation to 
the theta cycle, known as phase precession, could mediate sequence learning and novelty detection (Mehta et al., 1997; Lisman and Otmakhova, 2001). How these concepts might relate to anxiety-like behavior is unclear, except that most novel environments provoke anxiety.

A more straightforward link between theta and anxiety is suggested by a recent study of fear conditioning. Seidenbecher et al. (2003) examined local field potentials in the hippocampus and amygdala during the presentation of a fear-conditioned stimulus. During normal exploration and during presentation of an unconditioned tone, there was no evidence of theta-frequency oscillations in the amygdala, despite strong theta in the hippocampus. On presentation of a fear-conditioned tone, theta oscillations emerged in the amygdala, and these oscillations were tightly correlated with hippocampal theta. These findings suggest that theta oscillations can be propagated to downstream targets, likely attributable to the coordinated activity of output neurons in CA1 and the subiculum timed to the theta cycle. Thus, the increased theta magnitude seen here in $5-\mathrm{HT}_{1 \mathrm{~A}} \mathrm{R}$ knock-outs could lead to increased activity in downstream targets.

\section{Conclusion}

The findings described here demonstrate significant abnormalities in hippocampal activity in awake, behaving $5-\mathrm{HT}_{1 \mathrm{~A}} \mathrm{R}$ knockout mice. The magnitude of theta-frequency oscillations is increased in an anxiety-provoking environment and correlates with an anxiety-related behavioral variable. This increase appears to be related to anxiety, as opposed to novelty, because it persists on multiple exposures to the elevated plus maze. These findings suggest a role for hippocampal theta oscillations in the expression of anxiety-related behaviors. The results form a framework for additional study into the consequences of $5-\mathrm{HT}_{1 \mathrm{~A}} \mathrm{R}$ deletion on the neurophysiology of the neural circuits underlying anxiety.

Applying the current findings to the study of humans with anxiety disorders is theoretically straightforward. Theta oscillations are seen in human electroencephalograms, and, although the precise anatomical origins of these oscillations are still debated, they are thought to arise from corticolimbic interactions, perhaps driven by hippocampal theta (Basar et al., 2001; Kahana et al., 2001; Cantero et al., 2003). Conflicting reports differ on the relationship between theta in human electroencephalograms and anxiety traits or disorders (Mizuki et al., 1992, 1994; SaletuZyhlarz et al., 1997; Romano-Torres et al., 2002; Aftanas et al., 2003; Sachs et al., 2004). A drawback to many of these studies is that EEG recordings were obtained at rest or during cognitive tasks; the results reported here would suggest that symptom provocation studies might be an effective way to look for disorder-related increases in theta power in humans with anxiety disorders.

\section{References}

Aftanas LI, Pavlov SV, Reva NV, Varlamov AA (2003) Trait anxiety impact on the EEG theta band power changes during appraisal of threatening and pleasant visual stimuli. Int J Psychophysiol 50:205-212.

Andrade R, Nicoll RA (1987) Pharmacologically distinct actions of serotonin on single pyramidal neurones of the rat hippocampus recorded in vitro. J Physiol (Lond) 394:99-124.

Azmitia EC, Whitaker-Azmitia PM (1997) Development and adult plasticity of serotoninergic neurons and their target cells. In: Serotoninergic neurons and 5-HT receptors in the CNS (Baumgarten HG, Gothert M, eds), pp 1-40. Berlin: Springer.

Bannerman DM, Grubb M, Deacon RM, Yee BK, Feldon J, Rawlins JN (2003) Ventral hippocampal lesions affect anxiety but not spatial learning. Behav Brain Res 139:197-213.

Bannerman DM, Matthews P, Deacon RM, Rawlins JN (2004) Medial septal lesions mimic effects of both selective dorsal and ventral hippocampal lesions. Behav Neurosci 118:1033-1041.

Basar E, Schurmann M, Sakowitz O (2001) The selectively distributed theta system: functions. Int J Psychophysiol 39:197-212.

Boutrel B, Monaca C, Hen R, Hamon M, Adrien J (2002) Involvement of $5-\mathrm{HT}_{1 \mathrm{~A}}$ receptors in homeostatic and stress-induced adaptive regulations of paradoxical sleep: studies in $5-\mathrm{HT}_{1 \mathrm{~A}}$ knock-out mice. J Neurosci 22:4686-4692.

Buhl DL, Harris KD, Hormuzdi SG, Monyer H, Buzsaki G (2003) Selective impairment of hippocampal gamma oscillations in connexin-36 knockout mouse in vivo. J Neurosci 23:1013-1018.

Bullock TH, Buzsaki G, McClune MC (1990) Coherence of compound field potentials reveals discontinuities in the CA1-subiculum of the hippocampus in freely-moving rats. Neuroscience 38:609-619.

Buzsaki G (2002) Theta oscillations in the hippocampus. Neuron 33:325-340.

Buzsaki G, Buhl DL, Harris KD, Csicsvari J, Czeh B, Morozov A (2003) Hippocampal network patterns of activity in the mouse. Neuroscience 116:201-211.

Cantero JL, Atienza M, Stickgold R, Kahana MJ, Madsen JR, Kocsis B (2003) Sleep-dependent theta oscillations in the human hippocampus and neocortex. J Neurosci 23:10897-10903.

Chalmers DT, Watson SJ (1991) Comparative anatomical distribution of 5-HT1A receptor mRNA and 5-HT1A binding in rat brain-a combined in situ hybridisation/in vitro receptor autoradiographic study. Brain Res 561:51-60.

Csicsvari J, Hirase H, Czurko A, Mamiya A, Buzsaki G (1999) Fast network oscillations in the hippocampal CA1 region of the behaving rat. J Neurosci 19:RC20(1-4).

Csicsvari J, Jamieson B, Wise KD, Buzsaki G (2003) Mechanisms of gamma oscillations in the hippocampus of the behaving rat. Neuron 37:311-322.

Deacon RM, Bannerman DM, Rawlins JN (2002) Anxiolytic effects of cytotoxic hippocampal lesions in rats. Behav Neurosci 116:494-497.

Degroot A, Treit D (2003) Septal GABAergic and hippocampal cholinergic systems interact in the modulation of anxiety. Neuroscience 117:493-501.

Den Boer JA, Bosker FJ, Slaap BR (2000) Serotonergic drugs in the treatment of depressive and anxiety disorders. Hum Psychopharmacol 15:315-336.

Fernandes C, File SE (1996) The influence of open arm ledges and maze experience in the elevated plus-maze. Pharmacol Biochem Behav 54:31-40.

File SE, Gonzalez LE (1996) Anxiolytic effects in the plus-maze of 5-HT1Areceptor ligands in dorsal raphe and ventral hippocampus. Pharmacol Biochem Behav 54:123-128.

File SE, Zangrossi Jr H, Viana M, Graeff FG (1993) Trial 2 in the elevated plus-maze: a different form of fear? Psychopharmacology (Berl) 111:491-494.

File SE, Gonzalez LE, Andrews N (1996) Comparative study of pre- and postsynaptic $5-\mathrm{HT}_{1 \mathrm{~A}}$ receptor modulation of anxiety in two ethological animal tests. J Neurosci 16:4810-4815.

Gordon JA, Hen R (2004) The serotonergic system and anxiety. Neuromolecular Med 5:27-40.

Gray JA, McNaughton N (2000) The neuropsychology of anxiety, Ed 2. New York: Oxford UP.

Gross C, Zhuang X, Stark K, Ramboz S, Oosting R, Kirby L, Santarelli L, Beck S, Hen R (2002) Serotonin1A receptor acts during development to establish normal anxiety-like behaviour in the adult. Nature 416:396-400.

Heisler LK, Chu HM, Brennan TJ, Danao JA, Bajwa P, Parsons LH, Tecott LH (1998) Elevated anxiety and antidepressant-like responses in serotonin 5-HT1A receptor mutant mice. Proc Natl Acad Sci USA 95:15049-15054.

Hirose A, Tsuji R, Shimizu H, Tatsuno T, Tanaka H, Kumasaka Y, Nakamura M (1990) Inhibition by 8-hydroxy-2-(di-n-propylamino) tetralin and SM-3997, a novel anxiolytic drug, of the hippocampal rhythmical slow activity mediated by 5-hydroxytryptamine1A receptors. Naunyn Schmiedebergs Arch Pharmacol 341:8-13.

Holmes A, Rodgers RJ (1998) Responses of Swiss-Webster mice to repeated plus-maze experience: further evidence for a qualitative shift in emotional state? Pharmacol Biochem Behav 60:473-488.

Huerta PT, Lisman JE (1995) Bidirectional synaptic plasticity induced by a single burst during cholinergic theta oscillation in CA1 in vitro. Neuron 15:1053-1063.

Hyman JM, Wyble BP, Goyal V, Rossi CA, Hasselmo ME (2003) Stimula- 
tion in hippocampal region CA1 in behaving rats yields long-term potentiation when delivered to the peak of theta and long-term depression when delivered to the trough. J Neurosci 23:11725-11731.

Jacobs BL, Fornal CA (1997) Physiology and pharmacology of brain serotoninergic neurons. In: Serotoninergic neurons and 5-HT receptors in the CNS (Baumgarten HG, Gothert M, eds), pp 91-116. Berlin: Springer.

Kahana MJ, Seelig D, Madsen JR (2001) Theta returns. Curr Opin Neurobiol 11:739-744.

Kentros CG, Agnihotri NT, Streater S, Hawkins RD, Kandel ER (2004) Increased attention to spatial context increases both place field stability and spatial memory. Neuron 42:283-295.

Kitchigina VF, Kudina TA, Kutyreva EV, Vinogradova OS (1999) Neuronal activity of the septal pacemaker of theta rhythm under the influence of stimulation and blockade of the median raphe nucleus in the awake rabbit. Neuroscience 94:453-463.

Kjelstrup KG, Tuvnes FA, Steffenach HA, Murison R, Moser EI, Moser MB (2002) Reduced fear expression after lesions of the ventral hippocampus. Proc Natl Acad Sci USA 99:10825-10830.

Kocsis B, Bragin A, Buzsaki G (1999) Interdependence of multiple theta generators in the hippocampus: a partial coherence analysis. J Neurosci 19:6200-6212.

Kostowski W, Plaznik A, Stefanski R (1989) Intra-hippocampal buspirone in animal models of anxiety. Eur J Pharmacol 168:393-396.

Lisman JE, Otmakhova NA (2001) Storage, recall, and novelty detection of sequences by the hippocampus: elaborating on the SOCRATIC model to account for normal and aberrant effects of dopamine. Hippocampus 11:551-568.

Mann EO, Paulsen O (2005) Mechanisms underlying gamma (“40Hz") network oscillations in the hippocampus-a mini-review. Prog Biophys Mol Biol 87:67-76.

Marrosu F, Fornal CA, Metzler CW, Jacobs BL (1996) 5-HT1A agonists induce hippocampal theta activity in freely moving cats: role of presynaptic 5-HT1A receptors. Brain Res 739:192-200.

Maru E, Takahashi LK, Iwahara S (1979) Effects of median raphe nucleus lesions on hippocampal EEG in the freely moving rat. Brain Res 163:223-234.

McHugh SB, Deacon RM, Rawlins JN, Bannerman DM (2004) Amygdala and ventral hippocampus contribute differentially to mechanisms of fear and anxiety. Behav Neurosci 118:63-78.

McNaughton N, James DTD, Stewart J, Gray JA, Valero I, Drewnowski A (1977) Septal driving of hippocampal theta rhythm as a function of frequency in the male rat: effects of drugs. Neuroscience 2:1019-1027.

Mehta MR, Barnes CA, McNaughton BL (1997) Experience-dependent, asymmetric expansion of hippocampal place fields. Proc Natl Acad Sci USA 94:8918-8921.

Miller JS, Nonneman AJ, Kelly KS, Neisewander JL, Isaac WL (1986) Disruption of neophobia, conditioned odor aversion, and conditioned taste aversion in rats with hippocampal lesions. Behav Neural Biol 45:240-253.

Mizuki Y, Kajimura N, Kai S, Suetsugi M, Ushijima I, Yamada M (1992) Differential responses to mental stress in high and low anxious normal humans assessed by frontal midline theta activity. Int J Psychophysiol 12:169-178.

Mizuki Y, Suetsugi M, Ushijima I, Yamada M (1994) Characteristics of the anxiolytic effects of buspirone in high- and low-anxious normal humans assessed by frontal midline theta activity. Methods Find Exp Clin Pharmacol 16:291-300.

Monaca C, Boutrel B, Hen R, Hamon M, Adrien J (2003) 5-HT 1A/1B receptor-mediated effects of the selective serotonin reuptake inhibitor, citalopram, on sleep: studies in 5-HT 1A and 5-HT 1B knockout mice. Neuropsychopharmacology 28:850-856.

Murphy KR, Myors B (1998) Statistical power analysis: a simple and general model for traditional and modern hypothesis tests. Mahwah, NJ: Erlbaum.

Neumeister A, Bain E, Nugent AC, Carson RE, Bonne O, Luckenbaugh DA, Eckelman W, Herscovitch P, Charney DS, Drevets WC (2004) Reduced serotonin type 1A receptor binding in panic disorder. J Neurosci 24:589-591.

Nitz DA, McNaughton BL (1999) Hippocampal EEG and unit activity responses to modulation of serotonergic median raphe neurons in the freely behaving rat. Learn Mem 6:153-167.

Parks CL, Robinson PS, Sibille E, Shenk T, Toth M (1998) Increased anxiety of mice lacking the serotonin1A receptor. Proc Natl Acad Sci USA 95:10734-10739.
Parsons LH, Kerr TM, Tecott LH (2001) 5- $\mathrm{HT}_{1 \mathrm{~A}}$ receptor mutant mice exhibit enhanced tonic, stress-induced and fluoxetine-induced serotonergic neurotransmission. J Neurochem 77:607-617.

Pellow S, Chopin P, File SE, Briley M (1985) Validation of open: closed arm entries in an elevated plus-maze as a measure of anxiety in the rat. J Neurosci Methods 14:149-167.

Ponomarenko AA, Knoche A, Korotkova TM, Haas HL (2003) Aminergic control of high-frequency (approximately $200 \mathrm{~Hz}$ ) network oscillations in the hippocampus of the behaving rat. Neurosci Lett 348:101-104.

Ramboz S, Oosting R, Amara DA, Kung HF, Blier P, Mendelsohn M, Mann JJ, Brunner D, Hen R (1998) Serotonin receptor 1A knockout: an animal model of anxiety-related disorder. Proc Natl Acad Sci USA 95:14476-14481.

Rex A, Thomas H, Hortnagl H, Voits M, Fink H (2003) Behavioural and microdialysis study after neurotoxic lesion of the dorsal raphe nucleus in rats. Pharmacol Biochem Behav 74:587-593.

Robertson B, Baker GB, Vanderwolf CH (1991) The effects of serotonergic stimulation on hippocampal and neocortical slow waves and behavior. Brain Res 555:265-275.

Rodgers RJ, Dalvi A (1997) Anxiety, defence and the elevated plus-maze. Neurosci Biobehav Rev 21:801-810.

Rodgers RJ, Shepherd JK (1993) Influence of prior maze experience on behaviour and response to diazepam in the elevated plus-maze and light/ dark tests of anxiety in mice. Psychopharmacology (Berl) 113:237-242.

Romano-Torres M, Borja-Lascurain E, Chao-Rebolledo C, del-Rio-Portilla Y, Corsi-Cabrera M (2002) Effect of diazepam on EEG power and coherent activity: sex differences. Psychoneuroendocrinology 27:821-833.

Sachs G, Anderer P, Dantendorfer K, Saletu B (2004) EEG mapping in patients with social phobia. Psychiatry Res 131:237-247.

Saletu-Zyhlarz G, Saletu B, Anderer P, Brandstatter N, Frey R, Gruber G, Klosch G, Mandl M, Grunberger J, Linzmayer L (1997) Nonorganic insomnia in generalized anxiety disorder. 1. Controlled studies on sleep, awakening and daytime vigilance utilizing polysomnography and EEG mapping. Neuropsychobiology 36:117-129.

Sarnyai Z, Sibille EL, Pavlides C, Fenster RJ, McEwen BS, Toth M (2000) Impaired hippocampal-dependent learning and functional abnormalities in the hippocampus in mice lacking serotonin ${ }_{1 \mathrm{~A}}$ receptors. Proc Natl Acad Sci USA 97:14731-14736.

Seidenbecher T, Laxmi TR, Stork O, Pape HC (2003) Amygdalar and hippocampal theta rhythm synchronization during fear memory retrieval. Science 301:846-850.

Sibille E, Pavlides C, Benke D, Toth M (2000) Genetic inactivation of the serotonin $_{1 \mathrm{~A}}$ receptor in mice results in downregulation of major $\mathrm{GABA}_{\mathrm{A}}$ receptor alpha subunits, reduction of $\mathrm{GABA}_{\mathrm{A}}$ receptor binding, and benzodiazepine-resistant anxiety. J Neurosci 20:2758-2765.

Silveira MC, Sandner G, Graeff FG (1993) Induction of Fos immunoreactivity in the brain by exposure to the elevated plus-maze. Behav Brain Res 56:115-118.

Sodhi MS, Sanders-Bush E (2004) Serotonin and brain development. Int Rev Neurobiol 59:111-174.

Staubli U, Xu FB (1995) Effects of 5-HT3 receptor antagonism on hippocampal theta rhythm, memory, and LTP induction in the freely moving rat. J Neurosci 15:2445-2452.

Stefanski R, Palejko W, Bidzinski A, Kostowski W, Plaznik A (1993) Serotonergic innervation of the hippocampus and nucleus accumbens septi and the anxiolytic-like action of midazolam and 5-HT1A receptor agonists. Neuropharmacology 32:977-985.

Tada K, Kasamo K, Ueda N, Suzuki T, Kojima T, Ishikawa K (1999) Anxiolytic 5-hydroxytryptamine1A agonists suppress firing activity of dorsal hippocampus CA1 pyramidal neurons through a postsynaptic mechanism: single-unit study in unanesthetized, unrestrained rats. J Pharmacol Exp Ther 288:843-848.

Vanderwolf CH (1969) Hippocampal electrical activity and voluntary movement in the rat. Electroencephalogr Clin Neurophysiol 26:407-418.

Vanderwolf CH, Baker GB (1986) Evidence that serotonin mediates noncholinergic neocortical low voltage fast activity, non-cholinergic hippocampal rhythmical slow activity and contributes to intelligent behavior. Brain Res 374:342-356.

Vertes RP, Kocsis B (1997) Brainstem-diencephalo-septohippocampal systems controlling the theta rhythm of the hippocampus. Neuroscience 81:893-926. 
Vertes RP, Kinney GG, Kocsis B, Fortin WJ (1994) Pharmacological suppression of the median raphe nucleus with serotonin $1 \mathrm{~A}$ agonists, $8-\mathrm{OH}$ DPAT and buspirone, produces hippocampal theta rhythm in the rat. Neuroscience 60:441-451.

Vertes RP, Hoover WB, Viana Di Prisco G (2004) Theta rhythm of the hippocampus: subcortical control and functional significance. Behav Cogn Neurosci Rev 3:173-200.

Voigt JP, Rex A, Sohr R, Fink H (1999) Hippocampal 5-HT and NE release in the transgenic rat TGR(mREN2)27 related to behavior on the elevated plus maze. Eur Neuropsychopharmacol 9:279-285.

Wolff M, Costet P, Gross C, Hen R, Segu L, Buhot MC (2004) Agedependent effects of serotonin-1A receptor gene deletion in spatial learning abilities in mice. Brain Res Mol Brain Res 130:39-48.
Wyble BP, Hyman JM, Rossi CA, Hasselmo ME (2004) Analysis of theta power in hippocampal EEG during bar pressing and running behavior in rats during distinct behavioral contexts. Hippocampus 14:662-674.

Ylinen A, Bragin A, Nadasdy Z, Jando G, Szabo I, Sik A, Buzsaki G (1995) Sharp wave-associated high-frequency oscillation $(200 \mathrm{~Hz})$ in the intact hippocampus: network and intracellular mechanisms. J Neurosci $15: 30-46$.

Zhu XO, McNaughton N (1994) Effects of long-term administration of antidepressants on septal driving of hippocampal RSA. Int J Neurosci 79:91-98.

Zhu XO, McNaughton N (1995) Minimal changes with long-term administration of anxiolytics on septal driving of hippocampal rhythmical slow activity. Psychopharmacology (Berl) 118:93-100. 